\title{
Social responsibility of the hospitals in Isfahan city, Iran: Results from a cross-sectional survey
}

\author{
Mahmoud Keyvanara ${ }^{1}$, Haniye Sadat Sajadi ${ }^{*}$
}

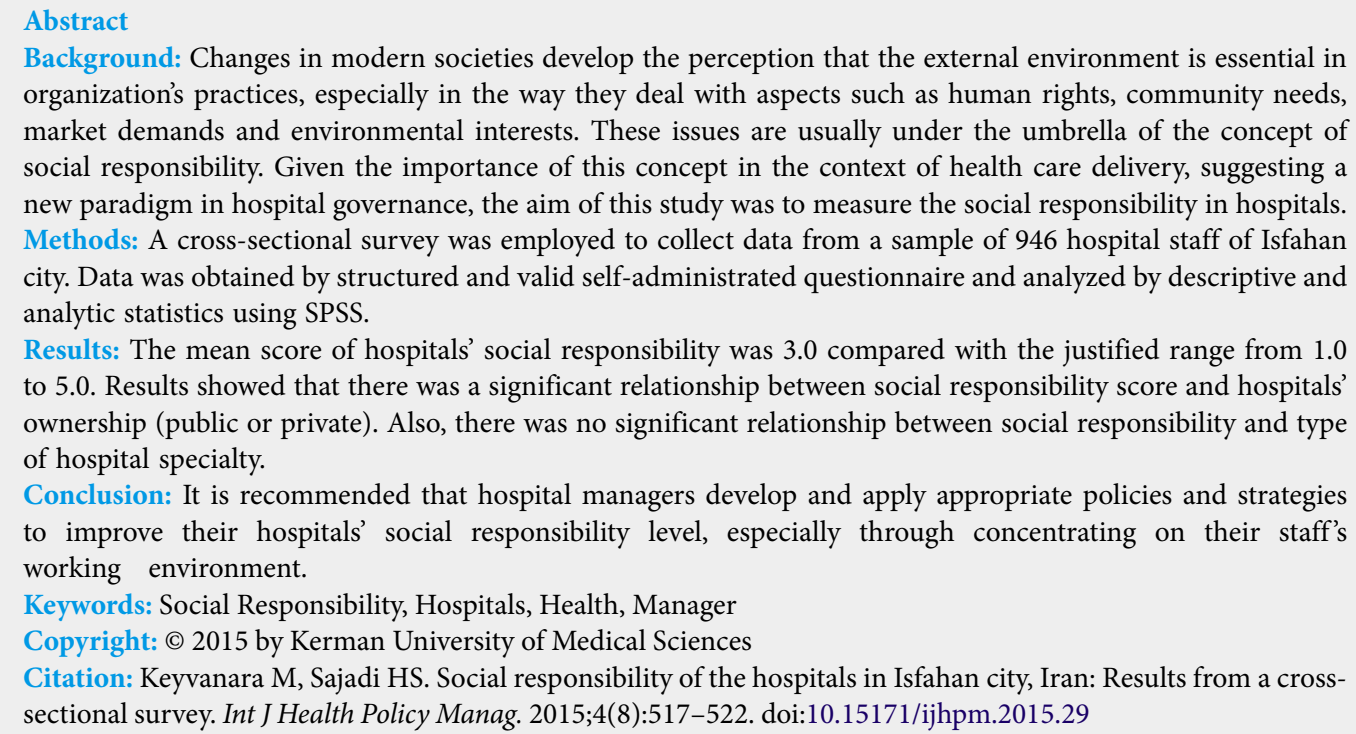

Background: Changes in modern societies develop the perception that the external environment is essential in organization's practices, especially in the way they deal with aspects such as human rights, community needs, market demands and environmental interests. These issues are usually under the umbrella of the concept of social responsibility. Given the importance of this concept in the context of health care delivery, suggesting a new paradigm in hospital governance, the aim of this study was to measure the social responsibility in hospitals. Methods: A cross-sectional survey was employed to collect data from a sample of 946 hospital staff of Isfahan city. Data was obtained by structured and valid self-administrated questionnaire and analyzed by descriptive and analytic statistics using SPSS.

Results: The mean score of hospitals' social responsibility was 3.0 compared with the justified range from 1.0 to 5.0. Results showed that there was a significant relationship between social responsibility score and hospitals' ownership (public or private). Also, there was no significant relationship between social responsibility and type of hospital specialty.

Conclusion: It is recommended that hospital managers develop and apply appropriate policies and strategies to improve their hospitals' social responsibility level, especially through concentrating on their staff's working environment.

Keywords: Social Responsibility, Hospitals, Health, Manager

Copyright: (c) 2015 by Kerman University of Medical Sciences

Citation: Keyvanara M, Sajadi HS. Social responsibility of the hospitals in Isfahan city, Iran: Results from a crosssectional survey. Int J Health Policy Manag. 2015;4(8):517-522. doi:10.15171/ijhpm.2015.29

Article History:

Received: 30 August 2014 Accepted: 9 February 2015 ePublished: 12 February 2015
*Correspondence to:

Email: H_sajadi@mail.mui.ac.ir

\section{Key Messages}

Implications for policy makers

- It is recommended that hospitals take actions to evaluate and improve their social responsibility which is a new governance approach. This helps them to create organizational value through performance, conformance and responsibility.

- Although top managers have the main role to take more social responsibility, staff participation is crucial in effectively carrying out the overall social responsibilities of the hospital.

- Public hospitals are expected to involve more in social and environmental activities as the main demands of today's modern societies.

Implications for public

In today's competitive market, there is a search for social responsible hospitals. If hospitals employ a systematic approach to monitor their social responsibility from the view of various stakeholders of hospitals, they will understand the current status in taking social responsibility as well as the gap between current and desired status. This helps them to think about required actions to improve their social functions which lead to better governance.

\section{Background}

Different changes happened in modern societies develop the perception that considering both internal and external organization's environment is essential in organization's practices. These issues are usually under the umbrella of the concept of "social responsibility". Social responsibility means that today's organizations must recognize their social responsibilities and should be receptive to them (1). There are several definitions for the concept of social responsibility of organizations (2). In a simple manner, the organization's social responsibility can be defined as the organization's involvement and participation in those actions that ultimately help to improve the social status (3). In these days of globalization taking social responsibility strategy could be a powerful tool for the sustainability and survival of any business (4).

Recently the concept of social responsibility has been addressed in the context of healthcare delivery (2). Like other organizations in the society, health sector and its organizations, with the mission of providing healthcare services, should engage in the social activities and take its 
social responsibility (5). Donohoe pointed to this issue by stating that to prevent the catastrophic environmental degradation and its social effects, which has the greatest negative impact on the health of individuals and the society, the role of health sector is more important than others (6). Abreu et al. also showed in another study that there is an urgent need for actions related to the social responsibility of the health sector and healthcare (7).

The concept of social responsibility is more highlighted in the hospital setting. As all know, hospitals are the strategic parts of the health sector $(8,9)$. Also, because of the extent and complexity of tasks, they have a complex structure with a wide variety of specialists. Therefore, their situation is different from other health organizations (10). Whatever happens inside a hospital is affected by all external conditions. So, hospitals are meant to take the social responsibility. This necessity has been shown by previous studies $(7,11)$. Furthermore, pressure from globalization and the competitive market make hospitals seek good hospital governance in which the social function of a hospital is redefined. Indeed, what is expected today from a hospital, is doing the right things and minimizing the potential damage to the stakeholders (11).

The review of studies related to the social responsibility showed that there are few studies in the healthcare organizations, but more in other organizations. The main objectives of those studies, which have been done beyond the health sector, were identifying suitable models for the social responsibility of the organizations (12-14), examining the relationship between the social responsibility and the financial performance (15) and the leadership styles (16), reviewing comments and attitudes of various groups about the social responsibility of the organizations (3,17-20), evaluating the initiatives of the organizations to increase the social responsibility $(21,22)$, and assessing the impact of the social responsibility on the organization $(23,24)$.

In studies conducted in the healthcare settings, the main objectives were recognized as developing a model for the hospital's social responsibility $(7,25,26)$, finding the social responsibilities and duties of the hospitals $(27,28)$ and identifying the incentives for hospitals to take social responsibility (29).

However, searching for social responsible organizations in today's societies which are governed by a sense of citizenship and civic consciousness indicates the importance of taking the social responsibility by hospitals (30). In fact, hospitals can and should be the first ones to follow this path and contribute to a fairer society and a safer environment. They should try to understand their mission in a global society, take more social responsibility and implement suitable initiatives to promote their social responsibility (11). Such movement needs to understand the current status of the hospital in relation to social responsibility. The need to examine the current status of social responsibility and the lack of empirical studies which focus on measuring this responsibility in the health sector, were the reasons which encouraged us to design this study with the aim of determining the level of social responsibility in hospitals. We hope this can help hospitals to identify their strength and weakness and help them to adopt required actions that may result in improving social responsibility.
Methods

Design

The present study was a cross-sectional descriptive one. It was conducted in Isfahan, Iran, 2012.

\section{Participants}

All staff of different hospitals in the city of Isfahan constituted the study population $(\mathrm{N}=8,300)$. City of Isfahan includes a total of 27 hospitals ( 11 academic, 8 private, 2 social welfare, 3 army and 3 charities affiliated). Due to problems with military hospitals for their cooperation in data collection and semiclosed nature of some charitable institutions, we excluded these hospitals from the study. Therefore, of 27 hospitals, 21 hospitals were selected as the study population. It is worth mentioning that these 21 hospitals were the most important centers in the city and accounted for a large percentage of their customers. By simple stratified sampling method, the sample consisted of the 946 staff.

\section{Data collection tools}

Data were collected using a self-administered valid and reliable questionnaire. To develop this questionnaire, the research team firstly carried out a comprehensive hard and soft copy resource searching. Following the result of those searches and that of previous related studies $(1,18)$, especially those which are about corporate social responsibility, we considered five different dimensions for the social responsibility and based on them measured the level of the social responsibility in the hospitals. These dimensions were as follows:

1. Leadership and inner processes which include the areas of mission and vision, policies and procedures, ethical codes, regulations and procedures;

2. Marketing that refers to suppliers and contractors, supply chain, consumer rights, responsibilities and liability management services including responsible purchasing;

3. Workplace environment which contains staff safety and health issues;

4. An environment which includes issues of sustainable development, pollution, waste management, energy saving and green purchasing management;

5. Community that states the local community, academic community in partnership with social institutions, partnership with Non-Governmental Organizations (NGOs), volunteer participation supporting activities of employee and charitable support.

Given these five dimensions and also after interviewing with three related experts, the initial questionnaire, which included 30 items, was prepared. This questionnaire was checked for content validity by seeking the views of 20 experts [ 10 health managers, 3 physicians who had management experience, 2 Ministry of Health (MoH) officers, 3 head nurses and 2 business managers]. Each expert was interviewed and asked to individually and independently evaluate and score each item for its appropriateness, representativeness and explicitness using a 5-point Likert Scale. Based on the feedback from the experts, each item of the questionnaire was assessed by Lawshe technique (31). Hence, 4 items were removed and 26 items remained in the final questionnaire. Additionally, the reliability was tested by a pilot study and the 
value of 0.95 for the Cronbach's alpha showed the reliability of the questionnaire.

The final questionnaire had three parts; the first part was questionnaire guide and demographic details, the second part included 3 closed items related to the profile of the hospitals and finally the last part consisted of 26 closed items measuring social responsibility in above 5 dimensions. The answers were arranged in five levels; very low, low, moderate, high, and very high. We assigned the following scores for the options: 1 for very low, 2 for low, 3 for moderate, 4 for high, and 5 for very high so that range of average score was from 1 to 5. According to this scoring, the mean score of total 26 items was considered as level of hospital social responsibility. Also, based on the expert's opinions, the research team decided that the mean score of less than 2.3, from 2.3 to 3.6 and above 3.6 on the total scale was evaluated as low, moderate and high social responsibility level, respectively.

\section{Data analysis}

The Statistical Package for Social Sciences version 16.0 for Windows (SPSS Inc., Chicago, IL, USA) was used.

\section{Results}

The responses of 755 staff that completely filled out the questionnaire were analyzed (response rate: 79.8\%). The average age of participants was 34.5 years. Of the 755 staff, 483 were male (64\%) and 272 were female (36\%). Most of the staff had university degrees (86\%) and were married (80\%). The hospitals under this study were $63 \%$ academic, $14.3 \%$ private and the rest social welfare. In terms of activity, most of them were general (76\%).

The mean score for the social responsibility of the hospitals in leadership and the internal processes, marketing, workplace, environmental and community's dimensions were obtained at 3.3, 3.1, 2.8, 3.0 and 2.8 respectively, which indicated that the level of the social responsibility in all dimensions was moderate. Overall, the mean score of the social responsibility was 3.0 which again indicated the level is moderate. The highest mean score of social responsibility was for an academic, special hospital (4.3) and the lowest score was in a private, general hospital (2.4). The social responsibility level of four hospitals (19\%) was high and others (81\%) were moderate (Table 1).

The independent T-Test test revealed that in all dimensions except the environmental dimension, there was a significant difference between mean scores of the social responsibility from the point of views of managers and staff $(P<0.050)$. Managers believed that they have fulfilled their social responsibility more than staff (Table 2). It is worth to mention that irrespective of different dimensions, the mean score obtained by managers and staff for the social responsibility was also significantly different $(P=0.003)$.

Regarding the type of hospital ownership, as we see in the Table 3, in all dimensions, there was a significant difference between the mean score and the type of hospital ownership $(P<0.050)$. Private hospitals had the highest score in all dimensions of social responsibility. Also, there was a significant difference between the mean score of social responsibility and the type hospital ownership $(P=0.000)$. The social responsibility in private hospitals was higher than academic and social welfare hospitals.

Finally, according to being general or special for the hospitals, the hypothesis test showed in all dimensions, there was no significant difference between the mean score and the type of activity in the hospitals $(P>0.050)$. Likewise, there was no significant difference in the mean score of the social responsibility of general and specialist hospitals $(P=0.917$; Table 4$)$.

Table 1. Studied hospitals: social responsibility

\begin{tabular}{|c|c|c|c|c|c|}
\hline \multirow{2}{*}{ Hospital } & \multirow{2}{*}{ Ownership* } & \multirow{2}{*}{ Activity $^{* *}$} & \multicolumn{2}{|c|}{ Social responsibility } & \multirow{2}{*}{$\begin{array}{c}\text { Social responsibility } \\
\text { level }{ }^{* * *}\end{array}$} \\
\hline & & & Mean & SD & \\
\hline $\mathrm{H} 1$ & $P$ & G & 3.7 & 0.6 & $\mathrm{H}$ \\
\hline $\mathrm{H} 2$ & $A$ & G & 2.9 & 0.5 & $M$ \\
\hline H3 & $A$ & G & 3.0 & 0.6 & $M$ \\
\hline $\mathrm{H} 4$ & $A$ & $\mathrm{~S}$ & 3.0 & 0.7 & $M$ \\
\hline H5 & $A$ & $\mathrm{~S}$ & 3.2 & 0.4 & M \\
\hline H6 & $\mathrm{P}$ & G & 3.8 & 0.7 & $\mathrm{H}$ \\
\hline $\mathrm{H} 7$ & $A$ & $\mathrm{~S}$ & 2.9 & 0.5 & M \\
\hline $\mathrm{H} 8$ & $\mathrm{~S}$ & G & 2.9 & 0.5 & M \\
\hline H9 & $A$ & $\mathrm{~S}$ & 3.1 & 0.5 & $M$ \\
\hline $\mathrm{H} 10$ & $S$ & G & 2.7 & 0.4 & M \\
\hline H11 & $A$ & G & 3.4 & 0.3 & M \\
\hline $\mathrm{H} 12$ & $A$ & G & 2.8 & 0.8 & $M$ \\
\hline $\mathrm{H} 13$ & $P$ & G & 3.4 & 0.3 & $M$ \\
\hline $\mathrm{H} 14$ & $P$ & G & 2.4 & 0.4 & M \\
\hline $\mathrm{H} 15$ & $A$ & G & 3.5 & 0.5 & $M$ \\
\hline $\mathrm{H} 16$ & $A$ & $\mathrm{~S}$ & 2.8 & 0.8 & $M$ \\
\hline $\mathrm{H} 17$ & $P$ & G & 3.3 & 0.6 & $M$ \\
\hline $\mathrm{H} 18$ & A & $\mathrm{S}$ & 4.3 & 0.3 & $\mathrm{H}$ \\
\hline $\mathrm{H} 19$ & $P$ & G & 3.9 & 0.7 & $\mathrm{H}$ \\
\hline $\mathrm{H} 20$ & $S$ & $\mathrm{G}$ & 2.8 & 0.6 & $M$ \\
\hline $\mathrm{H} 21$ & $A$ & G & 3.5 & 0.5 & $M$ \\
\hline
\end{tabular}

$\mathrm{SD}=$ Standard Deviation

${ }^{*} \mathrm{P}$ : Private, A: Academic, S: Social welfare hospitals

${ }^{* *} \mathrm{G}$ : General, S: Special hospitals

***L: Low, M: Moderate, H: High

Table 2. Participant differences: social responsibility and its dimensions

\begin{tabular}{lccccc}
\hline & \multicolumn{2}{c}{$\begin{array}{c}\text { Managers } \\
\mathbf{n}=\mathbf{5 1}\end{array}$} & \multicolumn{2}{c}{$\begin{array}{c}\text { Staff } \\
\mathbf{n}=\mathbf{7 0 4}\end{array}$} & \multirow{2}{*}{\begin{tabular}{c}
\multirow{2}{*}{ 2-tail. } \\
prob.
\end{tabular}} \\
\cline { 2 - 5 } & Mean & SD & Mean & SD & \\
\hline Social responsibility & 3.4 & 0.6 & 3.0 & 0.6 & 0.003 \\
Leadership and process & 3.6 & 0.7 & 3.3 & 0.7 & 0.044 \\
Marketing & 3.5 & 0.7 & 3.1 & 0.7 & 0.016 \\
Workplace & 3.3 & 0.8 & 3.0 & 0.8 & 0.003 \\
Environment & 3.3 & 0.6 & 3.0 & 0.7 & 0.110 \\
Community & 3.4 & 0.6 & 2.8 & 0.8 & 0.001 \\
\hline
\end{tabular}

$\mathrm{SD}=$ Standard Deviation; *Significant at 0.05 alpha level

Table 3. Ownership differences: social responsibility and its dimensions

\begin{tabular}{lccccccc}
\hline & \multicolumn{2}{c}{$\begin{array}{c}\text { Academic } \\
\text { medical }\end{array}$} & \multicolumn{2}{c}{ Private } & \multicolumn{2}{c}{$\begin{array}{c}\text { Social } \\
\text { welfare }\end{array}$} & \multirow{2}{*}{ *F-prob. } \\
\cline { 2 - 7 } & Mean & SD & mean & SD & mean & SD & \\
\hline Social responsibility & 3.0 & 0.6 & 3.4 & 0.6 & 2.8 & 0.7 & 0.000 \\
Leadership and & 3.3 & 0.8 & 3.5 & 0.7 & 3.0 & 0.7 & 0.000 \\
process & 3.1 & 0.7 & 3.5 & 0.6 & 3.0 & 0.6 & 0.000 \\
Marketing & 2.8 & 0.8 & 3.1 & 0.8 & 2.5 & 0.8 & 0.000 \\
Workplace & 3.0 & 0.8 & 3.4 & 0.8 & 2.8 & 0.8 & 0.000 \\
Environment & 2.7 & 0.8 & 3.2 & 0.8 & 2.6 & 0.9 & 0.000 \\
Community & $*$ & & & & & &
\end{tabular}

$\mathrm{SD}=$ Standard Deviation; * Significant at 0.05 alpha level 
Table 4. Activity differences: social responsibility and its dimensions

\begin{tabular}{lccccc}
\hline & \multicolumn{2}{c}{ General } & \multicolumn{2}{c}{ Special } & \multirow{2}{*}{ 2-tail. prob.* } \\
\cline { 2 - 5 } & Mean & SD & Mean & SD & \\
\hline Social responsibility & 3.0 & 0.7 & 3.0 & 0.6 & 0.917 \\
Leadership and process & 3.3 & 0.7 & 3.3 & 0.8 & 0.679 \\
Marketing & 3.1 & 0.7 & 3.1 & 0.7 & 0.868 \\
Workplace & 2.8 & 0.8 & 2.8 & 0.8 & 0.868 \\
Environment & 3.0 & 0.8 & 3.0 & 0.7 & 0.479 \\
Community & 2.8 & 0.9 & 2.8 & 0.9 & 0.903 \\
\hline
\end{tabular}

$\mathrm{SD}=$ Standard Deviation; *Significant at 0.05 alpha level

\section{Discussion}

The current study measured the level of social responsibility in hospitals. The results of this study demonstrated that the social responsibility of hospitals was moderate in level. That means more attention and effort are needed in order to increase this level. Previous studies also have emphasized this necessity. For example, Abreu et al. in their study in the hospitals of Portugal pointed to this necessity and recommended that as a complex organization, hospital must base its disclosure policy in transparency to allow patients to identify their own orientations (7). In another study in Bangladesh, the researcher proposed the healthcare centers should identify their social conditions of the society and act according to their social responsibilities. This improves the ability of providing healthcare services (32).

Some similar studies which have been performed beyond the health sector reported the moderate level of the social responsibility of the organizations. For instance, the findings of Panwar et al. research suggested that significant legitimacy and expectation gaps exist between societal respondents and industry managers, indicating managerial attention to the social and environmental issues facing the US forest products industry (3). The reports on the social responsibility in the selected banks in Bangladesh and in a group of Kazakh companies also expressed the undesirable social responsibility level in these under study organizations. Focusing on doing actions revealing the social responsibility of the organizations was recommended in these works $(20,22)$.

Although all these studies examined the social responsibility of their organizations by using different methods, but most of them concluded most investment in designing and implementing of the social responsibility is an issue that is focused by managers and customers $(3,24,33)$, especially in the health sector (26). Also, they emphasized that the implementation of these actions lead to the benefits of these organizations (29).

This study found that among five dimensions of the social responsibility, the dimension of leadership and internal process had received more attention. That means to operate according to the social responsibility, hospitals paid more attention to the following actions: developing and announcing the organization's mission and vision, policies and procedures, ethical codes, rules and regulations. Some of these actions like mission and vision formulations are basic requirements for every organizational change that through them, the required commitment of the senior management to the successful implementation of policies can be achieved $(27,29)$. Furthermore the needed participation in achieving the goals can be ensured $(26,34)$. These facts have been supported by previous studies were confirmed the need of mission, vision and values formulation $(7,19)$, awareness of customers about the organization mission and responsibilities $(6,27)$, and the importance of applied training in this field $(6,27,32)$.

The management commitment is one of the most important parts of the social responsibility. This has been shown by Kakabads and Rozuel in one of the local hospitals in France (25). Rohini also surveyed the social responsibility of five private hospitals in the city of Bangalore in India, and emphasized on the hospitals senior management role in social responsibility (35). So it can be said, although there are quiet necessary actions in the hospitals toward achieving the social responsibility, but they are not sufficient; hence, more attempts need to be done.

The marketing dimension came after leadership in ranking. This dimension also was evaluated at a moderate level, which indicated again the need of implementing further action regarding to this dimension. The previous studies have emphasized on the necessity of attention to these kinds of actions relating suppliers and contractors of supply chain, customers and consumers' rights, product liability responsibility and purchasing management.

Givel showed in his study that organizations should give attention not only to the shareholders, but also to other key stakeholders such as customers, community, suppliers and employees (36). Results of another study displayed that although the shareholders' theory in the $19^{\text {th }}$ century could satisfy the needs, but this theory is not applicable for today, and changes and modifications should be applied to it (37). The importance of considering the key stakeholders is such that positive interaction with the market has been introduced as one of the requirements for the organizational success. Therefore the role of key of stakeholders is essential in developing a model for the hospital social responsibility (25). Environmental dimension was placed in the third priority by the hospitals. The importance of the taking social responsibility corresponding to the environment, the necessity of operation in the manner which has least harm and damage to the environment and the positive impact of the social responsibility initiatives on sustainable development, reduction of pollution, waste management and energy saving management have been shown in many studies $(21,27,36,38)$. Regarding to the environment dimension, some studies have considered the role of healthcare organizations more important and suggested that in order to change to green centers, the health sector should carry out measures to protect the environment. These actions were a part of the organization plan to get converted into socially responsible organizations (28). Another study has also expressed to prevent a disaster, which Malthus has mentioned in it, the role of the health sector, especially its physicians, is more important than others (6).

The community and workplace dimensions have received the least attention in this study. Similar to this finding, inadequate evaluation of communication, coordination and partnership with communities, local and national organizations, which indicates undesirable levels of the community dimension of the social responsibility, were also obtained in another study (21). Note that the need of cooperation health service organizations with institutions involved in social activities and participation with relevant institutions has been confirmed in 
previous studies $(6,27,29)$.

Related to the workplace dimension, it has been shown that considering items such as staff safety and health, staff training and empowerment, human rights, decent work and briefly considering initiatives of promoting the workplace health provide a tool for the social control. This tool leads not only to attain more health of workers, but also leads to create a sustainable and responsible organization (39). Therefore, enforcement actions related to this dimension are needed to increase the social responsibility (40). Due to this fact that most of available resources in the health sector are human resources, this need is more noticeable.

The findings also revealed that managers reported more social responsibility than staff. Therefore, it can be concluded that managers are more optimistic about the social responsibility initiatives have been fulfilled in the hospitals. Hence, while managers think they have done their responsibilities to the global society, staff expects more efforts to improve the contribution to a better society. Moreover, it seems that managers have more involvement with social responsibility activities than staff and thus they are more aware about what have been done in the hospitals to improve social responsibility. This highlighted the importance of top management participation with staff in effectively carrying out the overall social responsibilities of the hospital. The importance of such participation to social responsibility improvement was also reported in Rohini study (35).

In this study, the social responsibility of private hospitals was higher than public hospitals. Public hospitals are owned by the government and receive government funding, while private ones are owned by a profit company or a non-profit organization and privately funded. It seems public hospitals try less than private one to attract customers and get a bigger market share. They mostly have own patients and provide free or cheap healthcare services to their patients. But private hospital should seek ways to build and increase the public trust and meet stakeholders' demands. Hence, they are more intent to involve social and environmental activities, which is one of the main demands of today's modern societies.

\section{Conclusion}

Along with the aim to increase productivity, paying attention to the social expectations and moral judgments as well as responding effectively to them, help hospitals to achieve their defined goals successfully. For that, the commitment of the hospital managers to ethical principles, attention and emphasis on universal moral principles, developing hospital ethics, appropriate measures consistent with the society demand and sensitivities and implementing ethics training program for managers and staff are some examples of activities that can be performed by the hospitals. In order to evaluate the effectiveness of these actions periodically, measuring the level of social responsibility in various hospitals seems to be necessary. Based on the results obtained in this study and in order to increase the social responsibility of the hospitals, following are recommended:

1. Planning and implementing the suitable mechanisms for attaining and improving the staff health, safety and welfare;

2. Holding more applied training courses for the staff in different categories;

3. More staff participation through some alternatives such as implementing the suggestion system;

4. Revision of the recruitment and retention systems of human resources;

5. The feasibility of implementing the family welfare programs;

6. The analytical reports preparation and publication, regarding the benefits and savings which results in implementation of policies and actions to protect the environment;

7. Studying, doing surveys and giving information about the environmental effect of the launch of new sections and new services;

8. Welcoming new ideas for delivering health services that have least damage to the environment;

9. Following up wisely to develop and implement strategies to improve consumption patterns;

10. Efforts to implement green management;

11. Paying attention to the hospital waste management.

\section{Limitations and implications for future research}

The level of social responsibility can be evaluated from two points of view; the external stakeholders (customers and society) and the internal stakeholders (managers, staff and shareholders). Evaluation of each of these perspectives can be performed separately by using some specific methods. In this study, we examined the level of social responsibility of a sample of hospital from the view of staff, because of time and financial limitations. Also, it was conducted at 21 hospitals in Isfahan city, Iran. Therefore, the findings should be interpreted with caution since the participants were hospital staff from a particular province of Iran and do not represent all hospital stakeholders in this country. More research in this area is needed before generalizing the study findings. Future research also needs to examine the level of the hospital's social responsibility from the point of both internal and external stakeholders and also to explore the variables that directly or indirectly influence and are influenced by social responsibility of hospitals that were not measured in the current study.

\section{Acknowledgments}

The authors gratefully acknowledge the reviewers for their constructive comments. The authors would also like to thank all hospital employees who took part in the study. This study was supported by The Social Determinants of Health Research Centre, Isfahan University of Medical Sciences, Isfahan, Iran (Grant No. 290074).

\section{Ethical Issues \\ Ethics approval was obtained from the Social Determinants of Health Research Centre of Isfahan University of Medical Sciences (IUMS). The participants were informed of the objective of the study. Moreover, they were reassured that their responses would be kept confidential and their identities would not be disclosed in any resulting publication.}

Competing interests

Authors declare that they have no competing interests.

Authors' contributions

MK participated in study design, contributed to data analysis and interpretation, as well as preparation of the manuscript. HSS conceived the study, carried out data collection, analysis and interpretation, and contributed to the writing and 
several editing of the manuscript. Both authors read and approved the final version of the paper.

\section{Authors' affiliations}

${ }^{1}$ Social Determinants of Health Research Centre, Isfahan University of Medical Sciences, Isfahan, Iran. ${ }^{2}$ Health Management and Economics Research Center, Isfahan University of Medical Sciences, Isfahan, Iran.

\section{References}

1. Salehiamiri SR, Hajiyani E, Omidvar A, Omidiyani SH, Khalili $\mathrm{M}$, Sasani $\mathrm{H}$, et al. Organization's social responsibility. Tehran: Research Institute of Strategic Researches; 2008.

2. Dahlsrud A. How corporate social responsibility is defined: an analysis of 37 definitions. Corporate Social Responsibility and Environmental Management 2008; 15: 1-13. doi: 10.1002/csr.132

3. Panwar R, Han X, Hansen E. A demographic examination of societal views regarding corporate social responsibility in the US forest products industry. Forest Policy and Economics 2010; 12 : 121-8. doi: 10.1016/j.forpol.2009.09.003

4. Chandrakala V. Measuring corporate social resposibility in Bengalure north district: A case study. International Journal of Entrepreneurship \& Business Environment Perspectives 2014; 2: $710-4$.

5. Evans R, Stoddart G. Producing health, consuming health care. Soc Sci Med 1990; 31: 1347-63. doi: 10.1016/02779536(90)90074-3

6. Donohoe M. Causes and health consequences of environmental degradation and social injustice. Soc Sci Med 2003; 56: 573-87. doi: 10.1016/s0277-9536(02)00055-2

7. Abreu R, David F, Crowther D, Date S, Exports M. Corporate social responsibility is urgently needed in health care. Social Responsibility Journal 2005; 1: 225-40. doi: 10.1108/eb045813

8. Upshur RE, Moineddin R, Crighton E, Kiefer L, Mamdani M. Simplicity within complexity: Seasonality and predictability of hospital admissions in the province of Ontario 1988-2001, a population-based analysis. BMC Health Serv Res 2005; 5: 13.

9. Sadaghiyani E. Hospital organization and management. Tehran: Jahanrayane Publication; 1998.

10. Dooley K. Organizational Complexity, International Encyclopedia of Business and Management. London: Thompson Learning; 2002.

11. Brandão C, Rego G, Duarte I, Nunes R. Social responsibility: a new paradigm of hospital governance? Health Care Anal 2013; 21: 390-402. doi: 10.1007/s10728-012-0206-3

12. Acar W, Aupperle K, Lowy R. An empirical exploration of measures of social responsibility across the spectrum of organizational types. International Journal of Organizational Analysis 2001; 9: 26-57. doi: 10.1108/eb028927

13. Daza JR. A valuation model for corporate social responsibility. Social Responsibility Journal 2009; 5: 284-99. doi: 10.1108/17471110910977230

14. Quazi A, O'Brien D. An empirical test of a cross-national model of corporate social responsibility. Journal of Business Ethics 2000; 25: 33-51.

15. McGuire J, Sundgren A, Schneeweis T. Corporate social responsibility and firm financial performance. Academy of Management Journal 1988; 31: 854-72. doi: 10.2307/256342

16. De Hoogh AH, Den Hartog DN. Ethical and despotic leadership, relationships with leader's social responsibility, top management team effectiveness and subordinates' optimism: A multimethod study. Leadersh Q 2008; 19: 297-311. doi: 10.1016/j. leaqua.2008.03.002

17. Maignan I. Consumers' perceptions of corporate social responsibilities: A cross-cultural comparison. Journal of Business Ethics 2001; 30: 57-72.

18. Maignan I, Ferrell OC. Nature of corporate responsibilities: Perspectives from American, French, and German consumers. Journal of Business Research 2003; 56: 55-67. doi: 10.1016/ s0148-2963(01)00222-3

19. Okada $Y$, Watanabe K. Social responsibility for the use of genes, genomes and biotechnology in biotechnology companies: $A$ commentary from the bioethical viewpoint. J Commer Biotechnol
2008; 14: 149-67. doi: 10.1057/jcb.2008.2

20. Potluri R, Batima Y, Madiyar K. Corporate social responsibility: a study of Kazakhstan corporate sector. Social Responsibility Journal 2010; 6: 33-44. doi: 10.1108/17471111011024531

21. Ettenborough M, Shyne J. Corporate Social Responsibility, Public Policy And the Oil Industry in Angola. 2003 [cited 2015 January 12]. Available from: http://siteresources.worldbank.org/INTPSD/ Resources/Angola/Angola_Petroleum_CSRsurvey.pdf

22. Khan M, Halabi A, Samy M. Corporate social responsibility (CSR) reporting: a study of selected banking companies in Bangladesh. Social Responsibility Journal 2009; 5: 344-57. doi: 10.1108/17471110910977276

23. Ellis $A D$. The impact of corporate social responsibility on employee attitudes and behaviors [PhD's thesis]. USA: Arizona State University; 2008.

24. Jatana R, Crowther D. Corporate Social Responsibility and the Empowerment of Women: An Indian Perspective. Social Responsibility Journal 2007; 3: 40-8. doi: 10.1108/17471110710840224

25. Kakabadse N, Rozuel C. Meaning of corporate social responsibility in a local French hospital: a case study. Society and Business Review 2006; 1: 77-96. doi: 10.1108/17465680610643364

26. Merali F. NHS managers' commitment to a socially responsible role: the NHS managers' views of their core values and their public image. Social Responsibility Journal 2005; 1: 38-46. doi: 10.1108/17465680610643364

27. Griffiths J. Environmental sustainability in the national health service in England. Public Health 2006; 120: 609-12. doi: 10.1016/j.puhe.2006.04.005

28. Kreisberg J. Green Healthcare in America: Just What are We Doing? Explore (NY) 2007; 3: 521-3. doi: 10.1016/j. explore.2007.07.008

29. Tudor TL, Bannister S, Butler S, White P, Jones K, Woolridge $\mathrm{AC}$, et al. Can corporate social responsibility and environmental citizenship be employed in the effective management of waste?: Case studies from the National Health Service (NHS) in England and Wales Resources. Conservation and Recycling 2008; 52: 764-74.

30. Crane A, Matten D. Business ethics: A European perspective. Managing corporate citizenship and sustainability in the age of globalisation. Oxford: Oxford University Press; 2004.

31. Lawshe $\mathrm{CH}$. A quantitative approach to content validity1. Pers Psychol 1975; 28: 563-75.

32. Bhuiyan A. O124 Community health providers and their social responsibility. Int J Gynaecol Obstet 2009; 107: S128-S. doi: 10.1016/s0020-7292(09)60496-3

33. Dincer C, Dincer B. Corporate Social Responsibility: Future Prospects in the Turkish Context. Social Responsibility Journal 2007; 3: 44. doi: 10.1108/17471110710835572

34. Merali F. Developing an explicit strategy towards social responsibility in the NHS. Journal of Health, Organization and Management 2006; 20: 309-24.

35. Rohini R, B. M. Social responsibility of hospitals: an Indian context. Social Responsibility Journal 2010; 6: 268-85. doi: 10.1108/17471111011051766

36. Givel M. Motivation of chemical industry social responsibility through Responsible Care. Health Policy 2007; 81: 85-92. doi: 10.1016/j.healthpol.2006.05.015

37. Post F. A response to "the social responsibility of corporate management: a classical critique". American Journal of Business 2003; 18: 25-35. doi: 10.1108/19355181200300002

38. Málovics G, Csigéné NN, Kraus S. The role of corporate social responsibility in strong sustainability. J Socio Econ 2008; 37 : $907-$ 18. doi: 10.1016/j.socec.2006.12.061

39. Holmqvist M. Corporate social responsibility as corporate social control: The case of work-site health promotion. Scandinavian Journal of Management 2009; 25: 68-72. doi: 10.1016/j. scaman.2008.08.001

40. Mittelmark M. Promoting social responsibility for health: health impact assessment and healthy public policy at the community level. Health Promot Int 2001; 16: 269. 